Supplement of Atmos. Chem. Phys., 21, 14833-14849, 2021

https://doi.org/10.5194/acp-21-14833-2021-supplement

(c) Author(s) 2021. CC BY 4.0 License.

(c) (i)

Atmospheric

Chemistry

and Physics

Supplement of

\title{
Trifluoroacetic acid deposition from emissions of HFO-1234yf in India, China, and the Middle East
}

\section{Liji M. David et al.}

Correspondence to: Liji M. David (liji.david@usu.edu), Mary Barth (barthm@ucar.edu), and A. R. Ravishankara (a.r.ravishankara@ colostate.edu)

The copyright of individual parts of the supplement might differ from the article licence. 
(i) GEOS-Chem
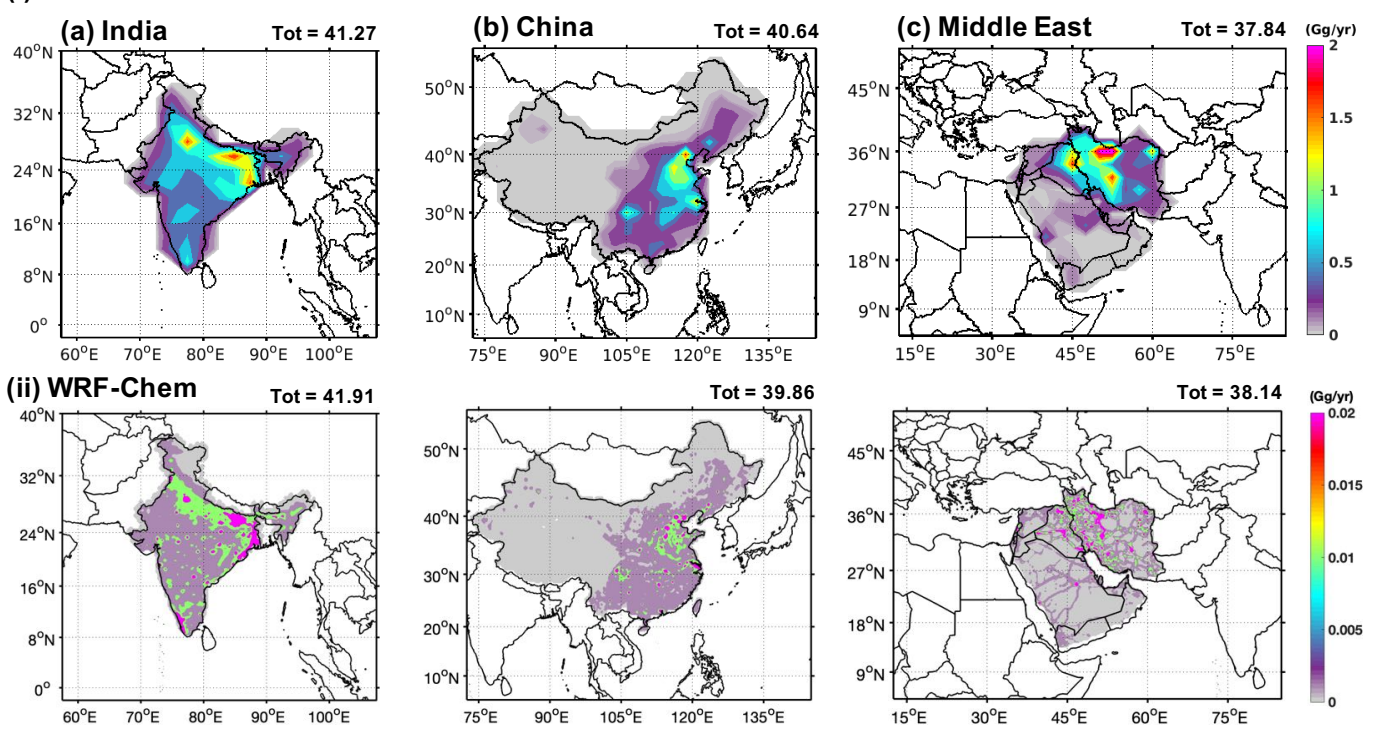

Figure S1. Annual spatial distribution of HFO-1234yf emission in the three regions in (i) GEOSChem and (ii) WRF-Chem. Grid total HFO-1234yf emissions are also shown in each figure in Gg

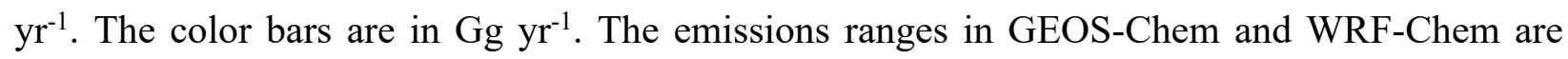
different because the grid sizes are much smaller in the latter than the former.

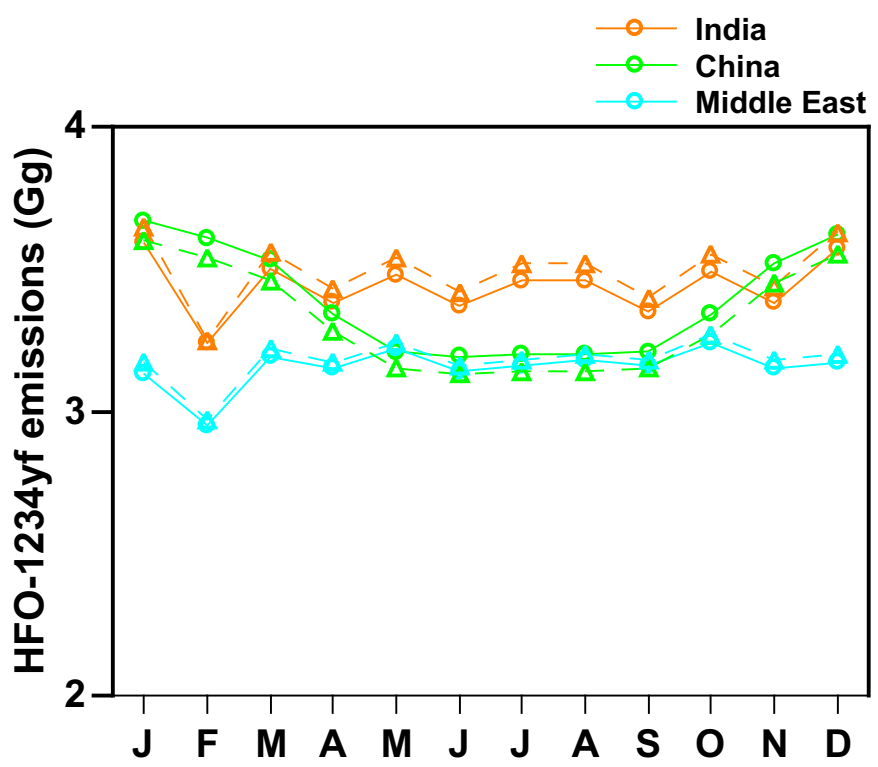

Figure S2. Monthly variation in HFO-1234yf emissions in GEOS-Chem (solid line with open circles) and WRF-Chem (dashed line with open triangles) in the three regions - India, China, and the Middle East. 


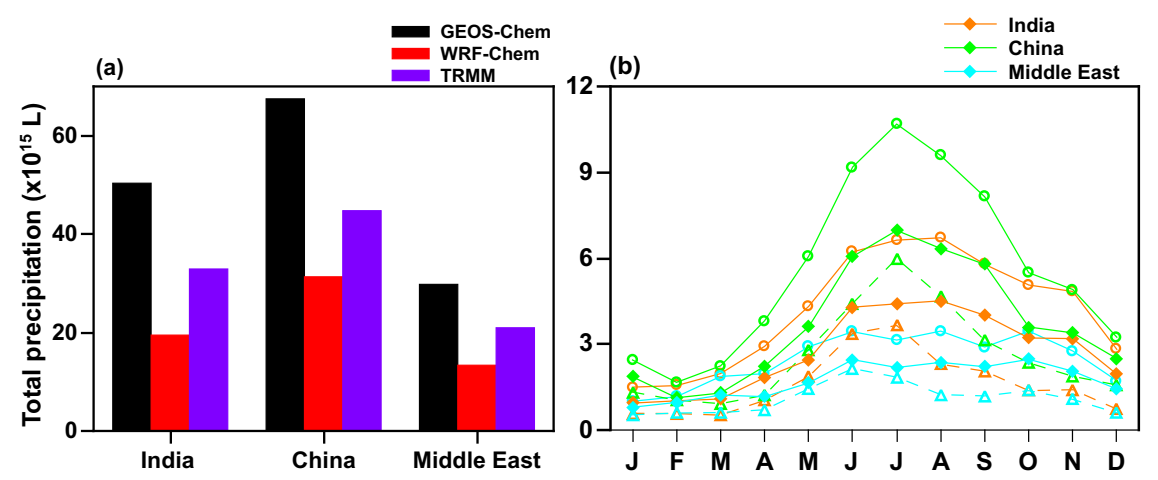

Figure S3. (a) Annual and (b) monthly total precipitation in GEOS-Chem and WRF-Chem in the three domains. GEOS-Chem results are solid line with open circles, WRF-Chem results are dashed line with open triangles, and TRMM observations are solid line with filled diamonds.
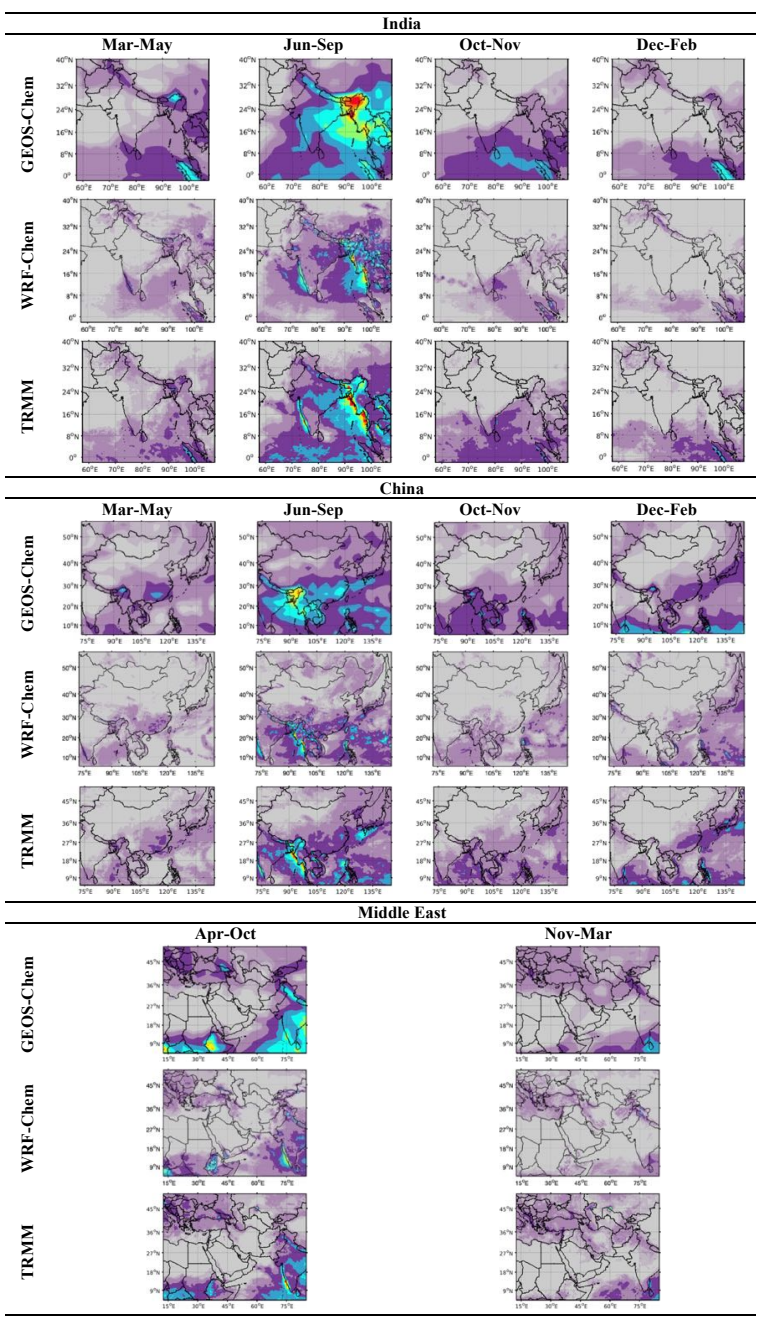

41 $\begin{array}{lllll}0 & 1000 & 2000 & 3000 & (\mathrm{~mm}) \\ 4000\end{array}$

42 Figure S4. Seasonal total precipitation $(\mathrm{mm})$ maps in the three domains from GEOS-Chem, WRF43 Chem, and TRMM observations. 


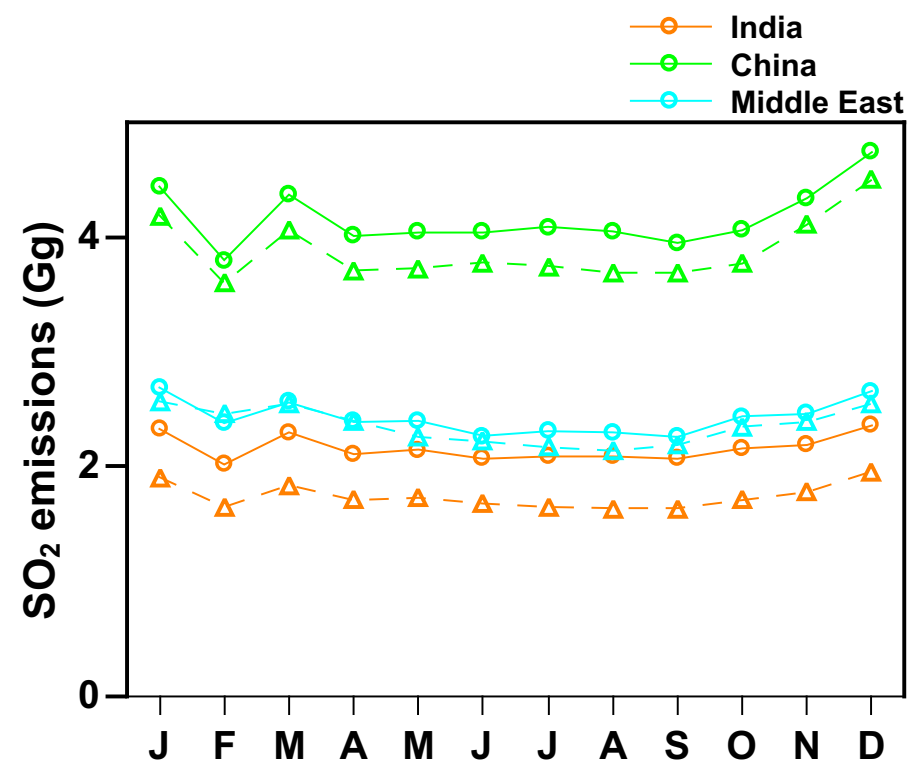

Figure S5. Monthly variation in $\mathrm{SO}_{2}$ emissions in GEOS-Chem (solid line with open circles) and WRF-Chem (dashed line with open triangles) from India, China, and the Middle East.

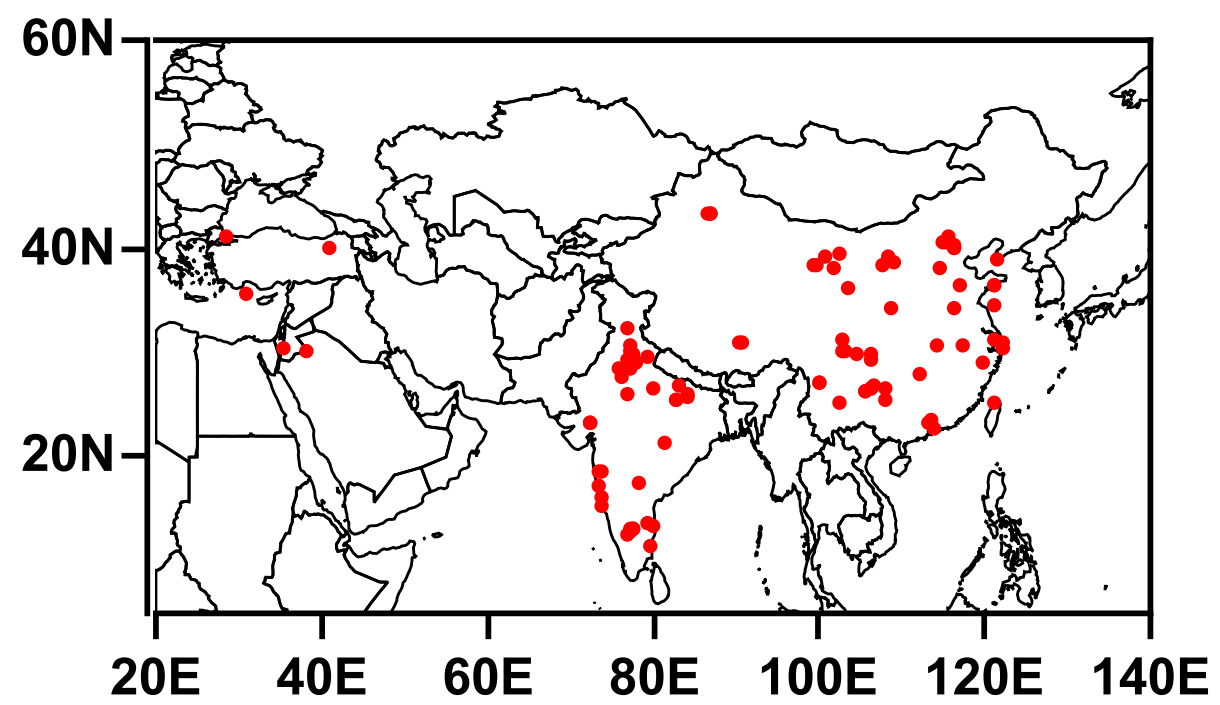

Figure S6. The location of sulfate rainwater concentration observations in the three domains for 2000-2015. 

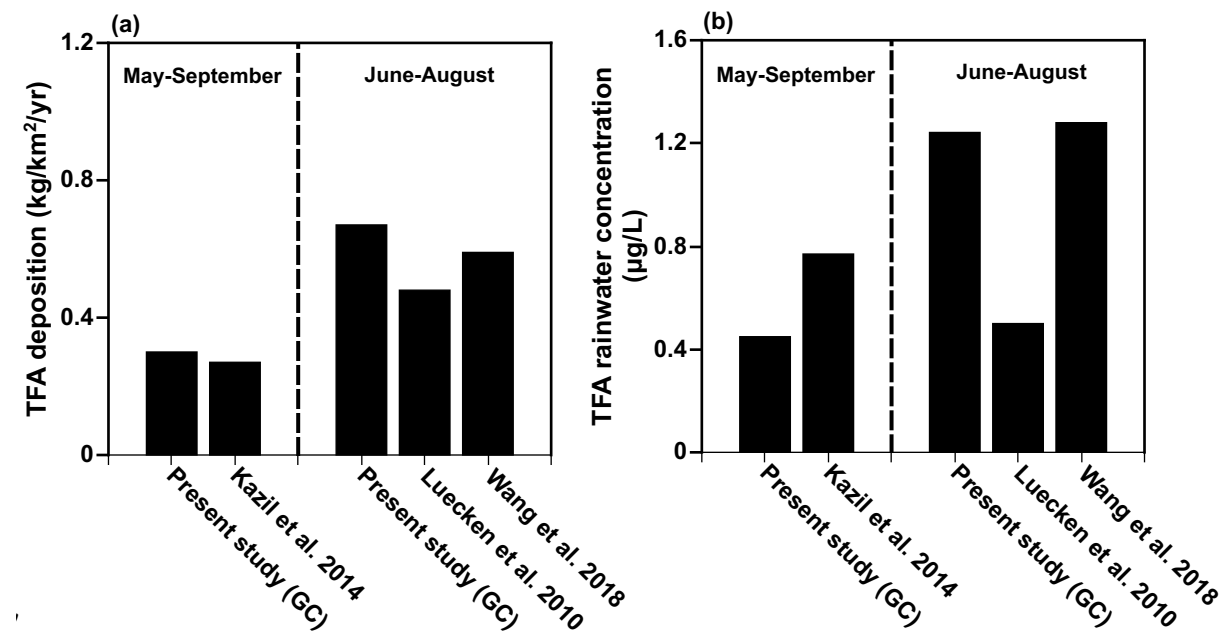

Figure S7. Comparison of TFA deposition and TFA rainwater concentration over the continental U.S. from the present study with the previous studies in summer. The emissions are normalized to $15.21 \mathrm{Gg} \mathrm{yr}^{-1}$.

(i) GEOS-Chem
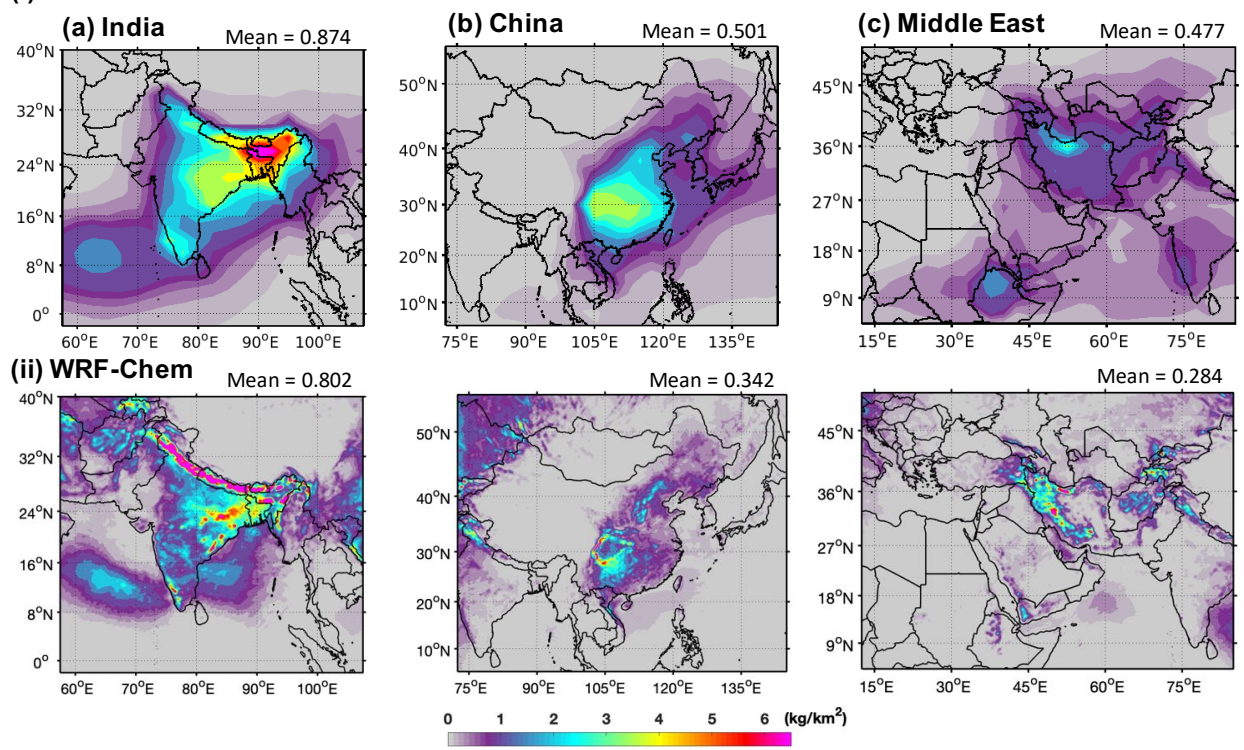

Figure S8. GEOS-Chem and WRF-Chem simulated annual total deposition rates of TFA $\left(\mathrm{kg} \mathrm{km}^{2}\right.$ $\mathrm{yr}^{-1}$ ) from dry and wet deposition in India, China, and the Middle East domains. The number at the top of each panel gives the mean deposition rates within the domains. 


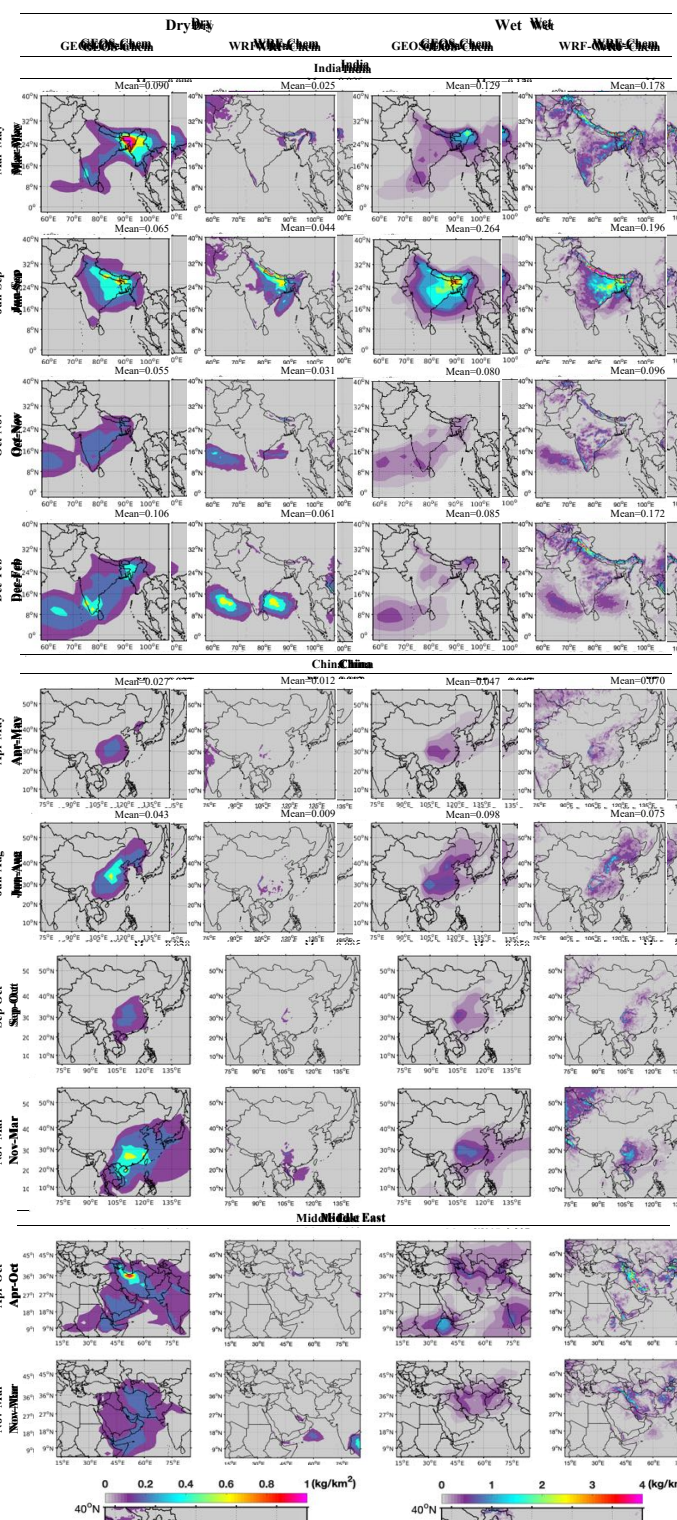

63

64 Figure S9. GEOS-Chem and WRF-Chem simulated seasonal variation in total deposition rates of 65 TFA from dry and wet deposition in India, China, and the Middle East domains. The number at 66 the top of each panel gives the mean dry and wet deposition rates $\left(\mathrm{kg} \mathrm{km}^{-2}\right)$ within the domains. 67 


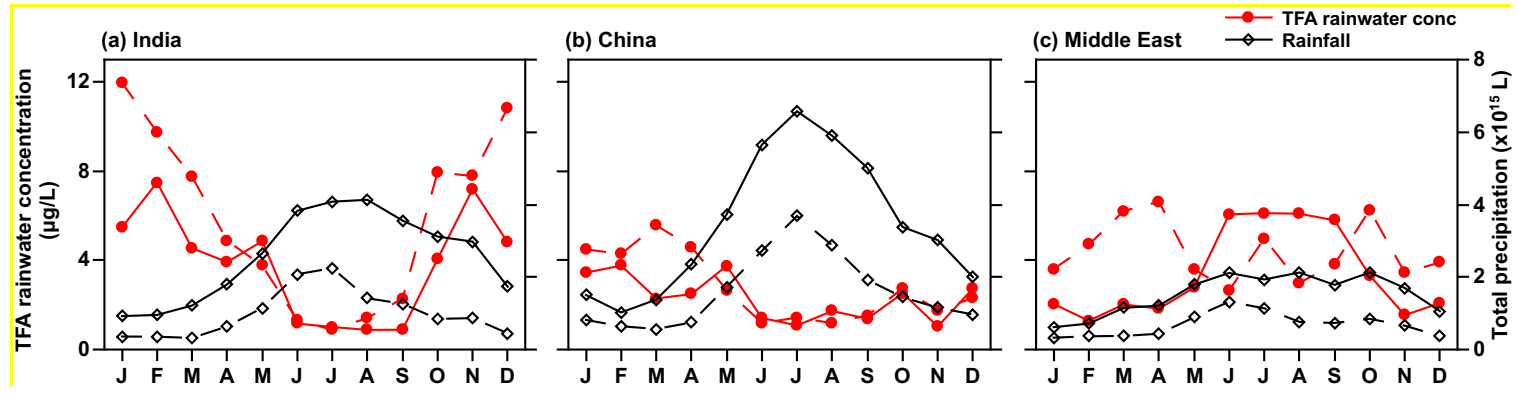

Figure S10. Monthly mean TFA rainwater concentration (filled circles) and total precipitation

70 (open diamonds) calculated from GEOS-Chem (solid lines) and WRF-Chem (dashed lines) over

71 (a) India, (b) China, and (c) the Middle East domains for emissions from those regions only.

72

73

74

75

76

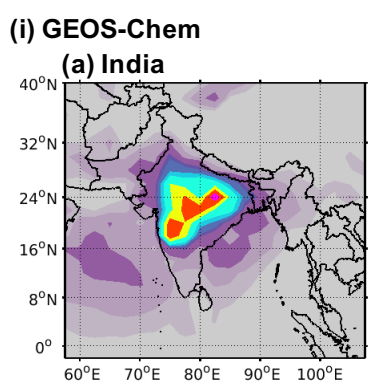

\section{(b) China}

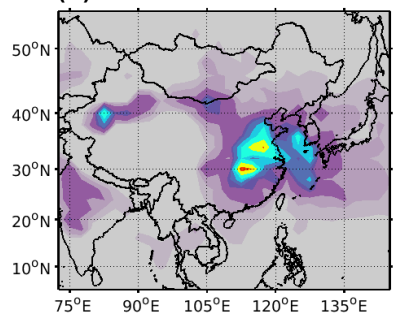

(ii) WRF-Chem

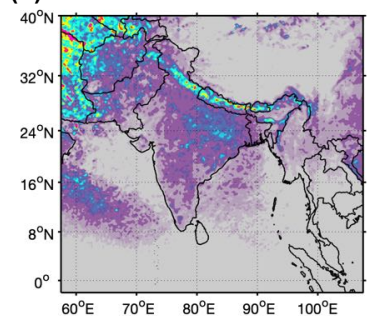

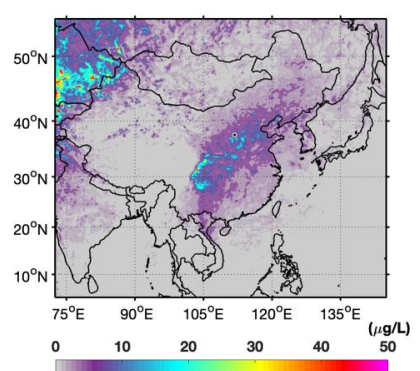
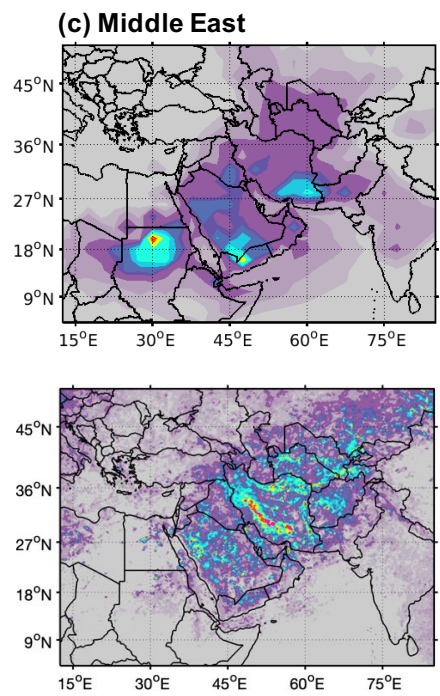

Figure S11. Contour maps of annual mean TFA rainwater concentrations in GEOS-Chem and WRF-Chem in the three domains. 


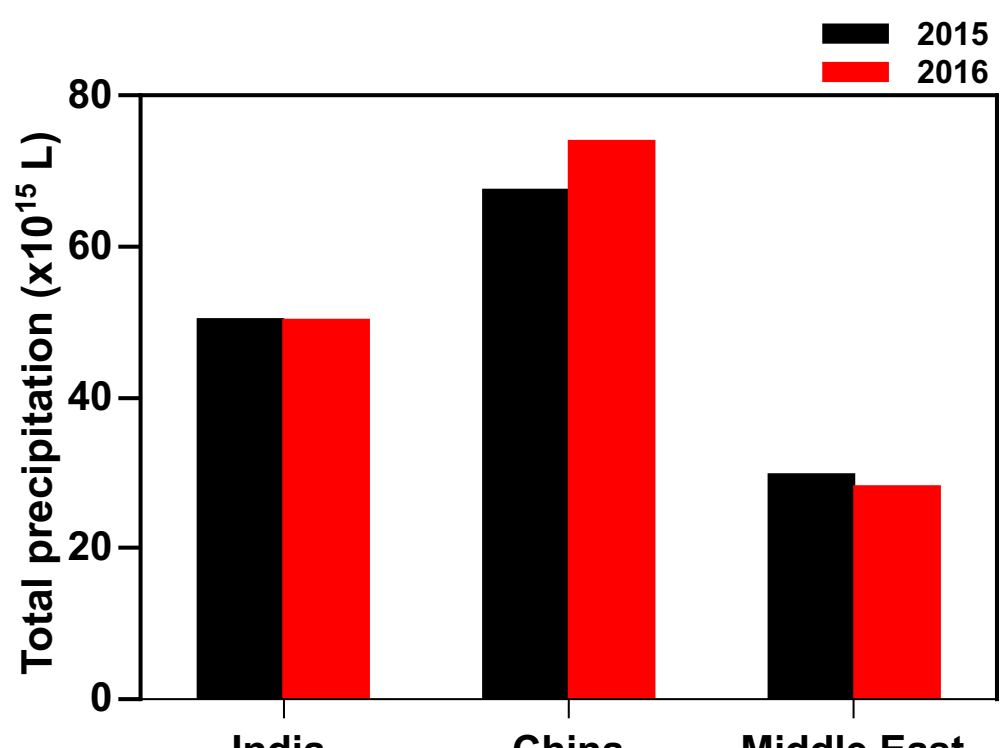

India

China

Middle East

78 Figure S12. Annual total precipitation in 2015 and 2016 from GEOS-Chem in the three domains.

79

80

81

82

83

84

85

86

87
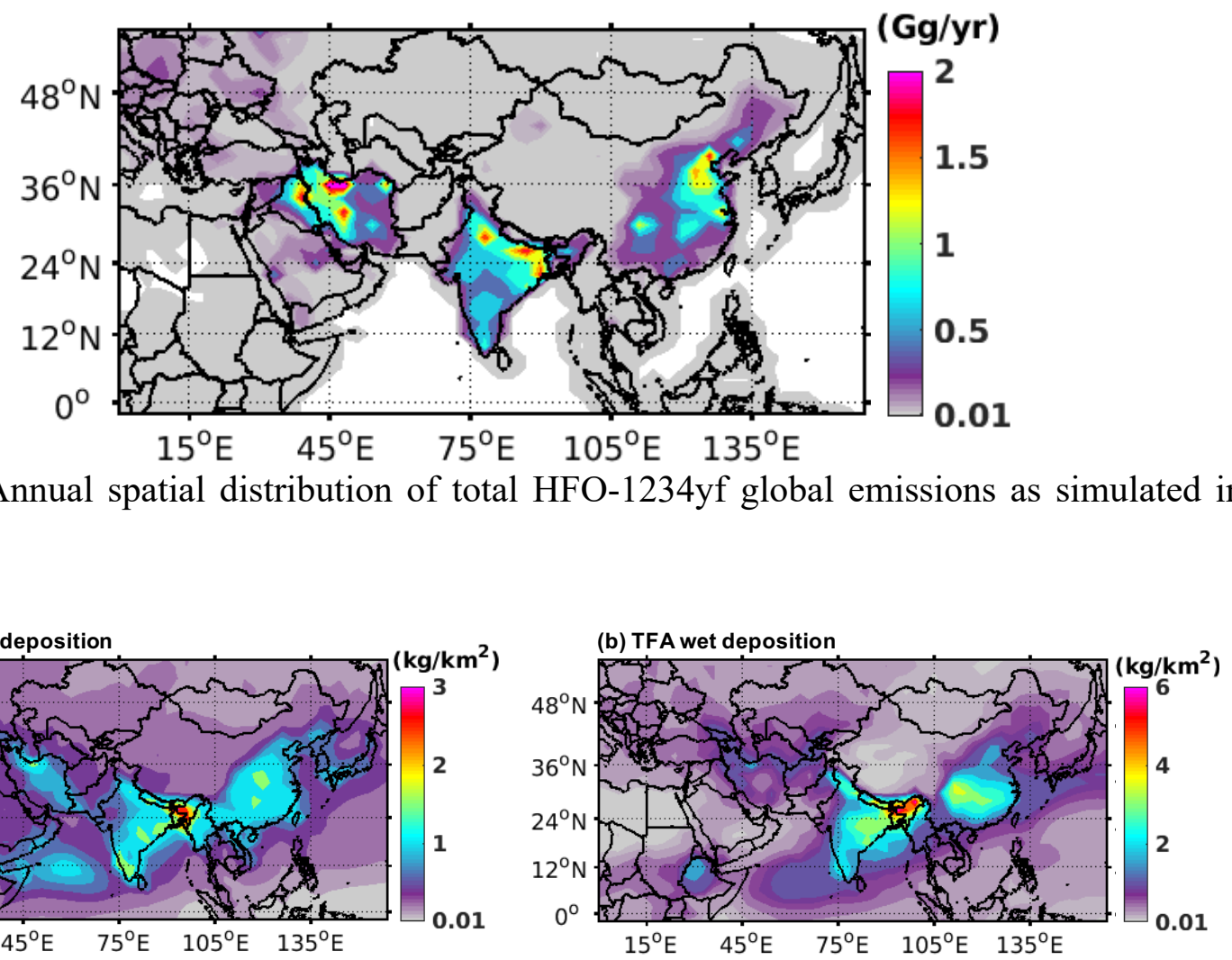

Figure S14. Annual total TFA (a) dry and (b) wet deposition from global HFO-1234yf emissions as simulated in GEOS-Chem. 


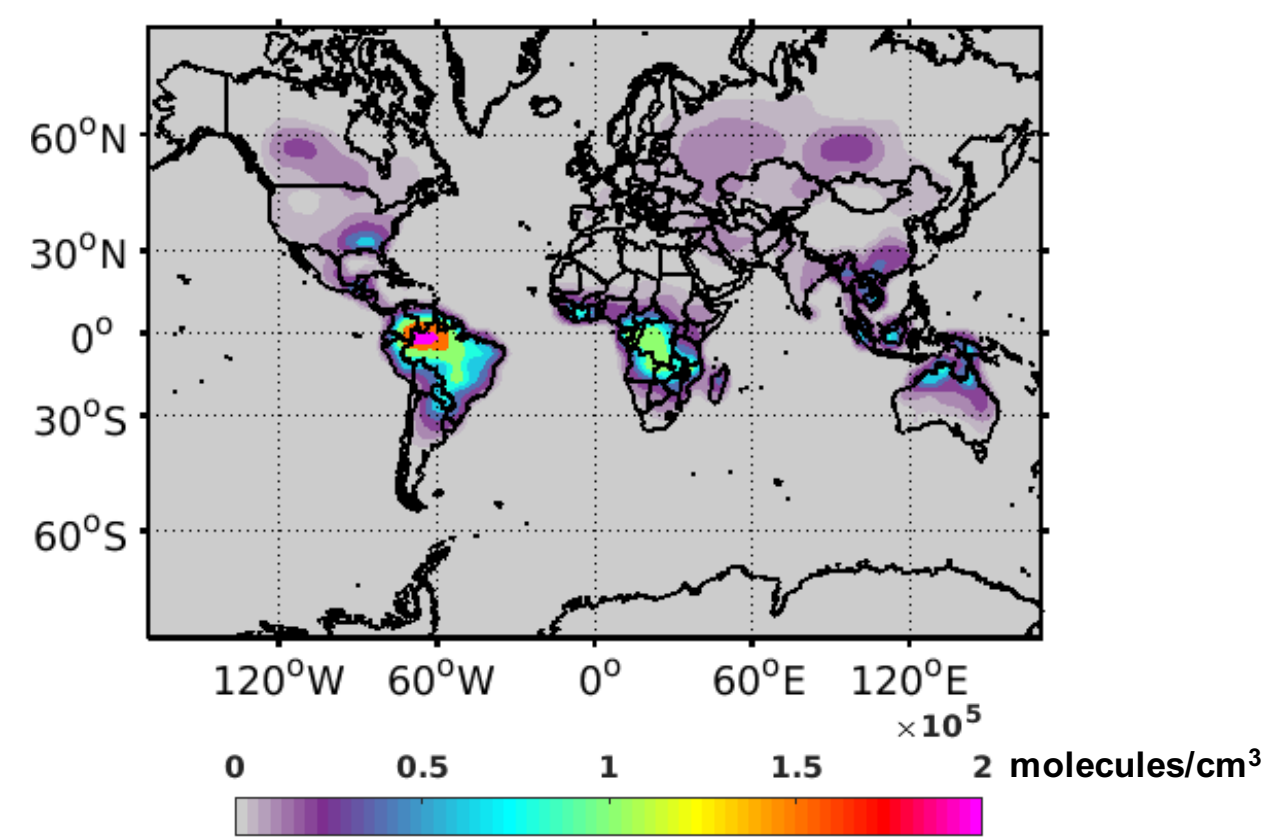

89 Figure S15. Mean surface Criegee intermediate concentration for seven months (January-July) 90 simulated using GEOS-Chem.

91

(a) India

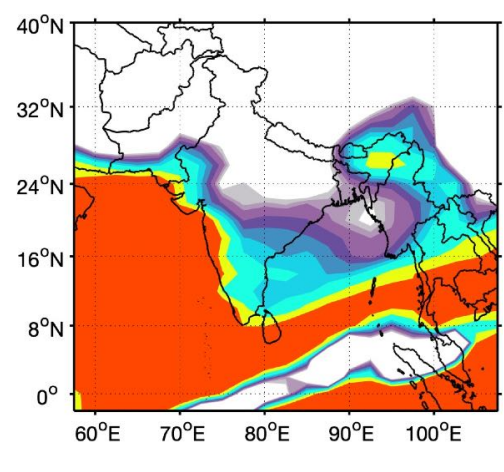

(b) China

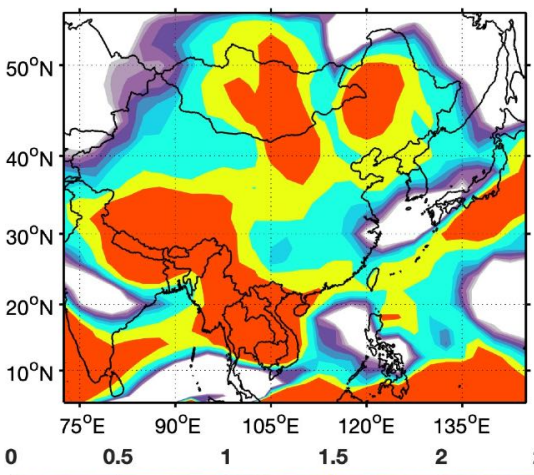

(c) Middle East

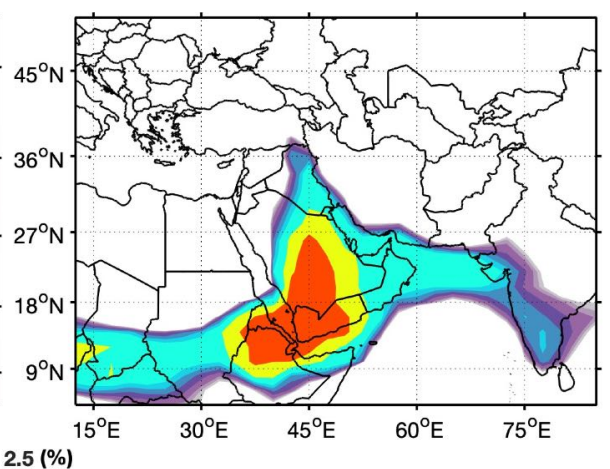

92

93

94

95

96

Figure S16. Percentage decrease in mean (January to July) surface TFA mixing ratio by including the reaction of Criegee intermediate with TFA. The changes are shown for HFO-1234yf emissions over each of the regions: (a) India, (b) China, and (c) the Middle East domains. 
97 Table S1. The model physics and chemistry options used in WRF-Chem.

\begin{tabular}{|l|c|c|c|}
\hline Domain & India & China & Middle East \\
\hline WRF Version & \multicolumn{2}{|c|}{4.1 .3 (released November2019) } \\
\hline Simulation period & \multicolumn{2}{|c|}{$11 / 01 / 2014-12 / 31 / 2015$} \\
\hline Meteorology & \multicolumn{2}{|c|}{$\begin{array}{c}\text { Global Forecast System at } 0.5^{\circ} \\
\text { Observational nudging every } 6 \text { hours }\end{array}$} \\
\hline Horizontal resolution & \multicolumn{2}{|c|}{$30 \mathrm{~km}$} \\
\hline Grid points (x, y, z) & $205 \times 197 \times 40$ & $315 \times 260 \times 40$ & $297 \times 242 \times 40$ \\
\hline Microphysics & \multicolumn{2}{|c|}{ Morrison two-moment scheme } \\
\hline Short/Longwave radiation & Rapid Radiative Transfer Model (RRTM) \\
\hline Land-surface & \multicolumn{2}{|c|}{ Noah Unified Land Surface Model } \\
\hline Boundary layer & \multicolumn{2}{|c|}{ Yonsei University } \\
\hline Cumulus scheme & \multicolumn{2}{|c|}{ Grell-Freitas } \\
\hline Chemical initial and boundary conditions & \multicolumn{2}{|c|}{ CAM-Chem and GEOS-Chem } \\
\hline Chemistry and Aerosol Scheme & \multicolumn{2}{|c|}{ MOZART-GOCART } \\
\hline Biogenic emissions & \multicolumn{2}{|c|}{ MEGANv2.04 } \\
\hline Anthropogenic emissions & \multicolumn{2}{|c|}{ EDGAR-HTAP } \\
\hline Wildfire emission & \multicolumn{2}{|c}{ FINNv1.6 } \\
\hline
\end{tabular}

98

99 Table S2. Seasonal TFA deposition (dry and wet) calculated from GEOS-Chem and WRF-Chem 100 in India, China, and the Middle East domains.

\begin{tabular}{ccccc}
\hline \multirow{2}{*}{ Seasons } & $\begin{array}{c}\text { GEOS-Chem } \\
\text { Dry }\end{array}$ & $\begin{array}{c}\text { WRF-Chem } \\
\text { Gry }\end{array}$ & Wet \\
\hline \multicolumn{5}{c}{ India } \\
\hline Mar-May & 0.798 & 1.14 & 0.190 & 1.37 \\
Jun-Sep & 0.423 & 1.73 & 0.259 & 1.17 \\
Oct-Nov & 0.740 & 1.11 & 0.402 & 1.19 \\
Dec-Feb & 0.972 & 0.773 & 0.543 & 1.39 \\
\hline \multicolumn{5}{c}{ China } \\
\hline Apr-May & 0.607 & 1.07 & 0.263 & 1.27 \\
Jun-Aug & 0.629 & 1.45 & 0.124 & 0.956 \\
Sep-Oct & 0.681 & 1.20 & 0.124 & 0.781 \\
Nov-Mar & 0.717 & 0.711 & 0.116 & 0.687 \\
\hline \multicolumn{5}{c}{ Middle East } \\
\hline Apr-Oct & 0.632 & 1.17 & 0.038 & 0.730 \\
Nov-Mar & 0.656 & 0.554 & 0.167 & 0.736 \\
\hline \multicolumn{5}{c}{}
\end{tabular}

